\title{
Antropologia e arquitetura: união para o futuro
}

\author{
Anthropology and architecture: union for the future \\ Antropología y arquitectura: unión para el futuro
}

Recebido: 30/09/2021 | Revisado: 09/10/2021 | Aceito: 14/10/2021 | Publicado: 17/10/2021

\author{
Daiane dos Santos Pereira \\ ORCID: https://orcid.org/0000-0002-2054-5257 \\ Faculdades Santo Agostinho, Brasil \\ E-mail: daianepereira3124@ outlook.com \\ Philipe do Prado Santos \\ ORCID: https://orcid.org/0000-0001-5671-2881 \\ Faculdades Santo Agostinho, Brasil \\ E-mail: philipe.prado@hotmail.com
}

\begin{abstract}
Resumo
Este artigo mostra a partir de pesquisas baseadas em estudos e análises de artigos diversos e espaços urbanos a fim de entender como a antropologia estuda o ser humano em diversos âmbitos enquanto a arquitetura também o analisa e utiliza-se dos estudos antropológicos para projetar o espaço urbano e o lar de cada cidadão, juntamente com diversas análises de forma e cores capazes de estimular necessidades e ações dos usuários. Assim, o trabalho tem como objetivo esclarecer a necessidade dos estudos antropológicos nos projetos urbanos e habitacionais. Concluindo então, que com uma investigação mais profunda das duas disciplinas fica perceptível a importância de uma para outra e como poderia ser criada uma disciplina em que se unam o debate de ambas para que o espaço urbano se torne cada vez mais acolhedor e útil, diminuindo os problemas sociais, além de ser mais confortável e sustentável para os indivíduos e o meio ambiente.
\end{abstract}

Palavras-chave: Ambiente; Antropologia; Arquitetura; Sociedade; Urbanismo.

\begin{abstract}
This article shows from research based on studies and analysis of various articles and urban spaces in order to understand how anthropology studies the human being in different areas while architecture also analyzes it and uses anthropological studies to design urban space and the home of each citizen, together with several analyzes of shape and colors capable of stimulating the needs and actions of the users. Thus, the work aims to clarify the need for anthropological studies in urban and housing projects. Concluding, then, that with a deeper investigation of the two disciplines, the importance of one to the other becomes noticeable and how a discipline could be created in which the debate of both unites so that the urban space becomes increasingly welcoming and useful, decreasing social problems, in addition to being more comfortable and sustainable for individuals and the environment.
\end{abstract}

Keywords: Anthropology; Architecture; Environment; Society; Urbanism.

\section{Resumen}

Este artículo parte de una investigación basada en estudios y análisis de diversos artículos y espacios urbanos con el fin de comprender cómo la antropología estudia al ser humano en diferentes ámbitos mientras que la arquitectura también lo analiza y utiliza los estudios antropológicos para diseñar el espacio urbano y el hogar de cada ciudadano, en conjunto. con diversos análisis de formas y colores capaces de estimular las necesidades y acciones de los usuarios. Así, el trabajo tiene como objetivo aclarar la necesidad de estudios antropológicos en proyectos urbanos y habitacionales. Concluyendo, entonces, que con una investigación más profunda de las dos disciplinas, se hace notar la importancia de una para la otra y cómo se podría crear una disciplina en la que el debate de ambas se una para que el espacio urbano se vuelva cada vez más acogedor y útil, disminuyendo socialmente. problemas, además de ser más cómodos y sostenibles para las personas y el medio ambiente.

Palabras clave: Antropología; Arquitectura; Medio Ambiente; Sociedad; Urbanism.

\section{Introdução}

A antropologia é o estudo do ser humano nos aspectos culturais, sociais e biológicos. As áreas citadas são tão amplas que existem estudos específicos para cada uma delas com diferentes níveis de análise. Ademais, de acordo com o departamento de antropologia da Universidade de São Paulo (USP) (2007?): 
Qualquer que seja a definição adotada é possível entender a antropologia como uma forma de conhecimento sobre a diversidade cultural, isto é, a busca de respostas para entendermos o que somos a partir do espelho fornecido pelo "Outro"; uma maneira de se situar na fronteira de vários mundos sociais e culturais, abrindo janelas entre eles, através das quais podemos alargar nossas possibilidades de sentir, agir e refletir sobre o que, afinal de contas, nos torna seres singulares, humanos.

É uma ciência social que teve nos últimos séculos várias teorias que vão desde a análise de povos e o porquê de alguns serem dominados por outros a até questões de evolucionismo cultural, por exemplo. É uma disciplina mais culturalista do que a sociologia, abrangendo todo um agrupamento ou segmento social e não somente o homem em si.

Para buscar uma definição para a arquitetura é ir além do significado concreto, mas pensar nesta arte indispensável como um instrumento de transformação humanitária, tanto em caráter sucinto e individual como uma residência ou algo grandioso e coletivo como o Coliseu, anfiteatro romano tido como um dos maiores símbolos da Roma antiga destinado para entretenimento da população.

No sentido da palavra arquitetura, sua origem grega define bem a profissão em si, onde em uma tradução direta para a língua portuguesa, possui significado: “construtor chefe”. Uma espécie de arte da construção, a arquitetura sempre esteve interligada à evolução do homem, onde este em busca de abrigo e proteção começara a desenvolver suas ideias construtivas na intenção de criar um local para que se refugiasse nos momentos necessários. Consequentemente, com passar dos anos a humanidade evolui e vê uma premência em demandas sociais coletivas, assim, a arquitetura progride junto ao homem.

A união da arquitetura e da antropologia acontece cotidianamente no uso dos espaços, seja pela análise física do ser humano para as normas de tamanho do espaço ou pelo aspecto cultural e social, que dão forma às zonas públicas e permitem que possam ser concebidas de maneira que atenda ao máximo de pessoas possível. Segundo Alessia de Biase (2018), antropóloga e arquiteta, são “duas disciplinas, uma em que o espaço está no centro das preocupações e a outra em que o espaço é o contexto das interações." Além disso, a autora afirma que a história mostra diversos encontros da antropologia com a arquitetura, podendo até mesmo algum dia um campo disciplinar próprio ser fundido.

Percebe-se então que são deixados "marcadores" pelo tempo. São eles as diversas maneiras de habitar, distribuir e transformar um espaço em certos períodos, marcas da relação do ser humano com o ambiente em que ele vive. Isso pode ser visto a partir dos estilos arquitetônicos de cada época. No modernismo, por exemplo, as habitações eram pensadas como uma área de produção em que os ambientes deveriam ser o mais simples possível de forma a facilitar e acelerar os processos que ali ocorreriam diariamente. Uma frase conhecida do estilo é a do arquiteto alemão Mies van der Rohe: "Menos é mais".

Assim, observa-se que ambas as disciplinas já vêm andando juntas na história e devem continuar de tal maneira que possam algum dia se tornar uma disciplina a ser estudada nas faculdades de antropologia e principalmente de arquitetura.

\section{Metodologia}

O estudo tem abordagem qualitativa, visto que não há preocupação com a representatividade numérica, mas, com o aprofundamento da compreensão dos significados e intencionalidades da união das disciplinas de antropologia e arquitetura e urbanismo. Tem foco na interpretação das pesquisas feitas juntamente às observações realizadas, que buscam compreender os contextos socioculturais e ambientais dos espaços urbanos. Além disso, visa caracterizar o comportamento cultural dos brasileiros e dos demais povos em geral quanto a habitação e uso do meio urbano.

O método utilizado para o trabalho é o hipotético-dedutivo com o propósito de pesquisa exploratória a fim de analisar os problemas atuais da urbanização que não leva em conta, muitas vezes, as questões culturais dos indivíduos que ali viverão. A finalidade é alcançar os objetivos propostos, explícitos anteriormente.

Para tanto, a pesquisa baseia-se em estudos e análises de dados secundários, pesquisa bibliográfica de diversos autores, entre antropólogos, arquitetos e urbanistas, bem como mestres e doutores de diversas áreas da ciência. Também foram 
analisados dados obtidos através de visitas técnicas em diferentes espaços urbanos do Brasil. O trabalho de campo deu-se pelo contato direto com os ambientes pesquisados por meio da observação das ações dos usuários e funcionários, além dos elementos físicos ali dispostos e suas interrelações. Como objetos empíricos, estão, por exemplo, a Avenida Paulista na cidade de São Paulo, o Centro da cidade de Vitória da Conquista e ao pequeno distrito de Paranapiacaba no estado de São Paulo.

A partir dos dados e informações encontrados nas pesquisas bibliográficas, e nas observações de campo, por meio de visitas técnicas, foi feita a análise da necessidade de uma amplificação do estudo das culturas e da sociedade em si para uma melhor urbanização e melhor aproveitamento dos espaços. Conferindo assim, uma menor desigualdade social e mais sustentabilidade, bem como um espaço com capacidade de agradar a uma quantidade maior de pessoas.

\section{Resultados e Discussão}

\subsection{Relação entre arte e ciência}

A relação entre Arte e Ciência é discutida em diversas épocas e muito se disse entre ambas serem totalmente diferentes não havendo relação uma com a outra. Porém, nos últimos anos, estudiosos procuram mostrar que é uma relação de “combinação das forças dos dois” como diz o antropólogo e professor, Stéphane Malysse (2007).

A arquitetura faz parte do cotidiano do ser humano, desta forma, necessita-se que ela seja uma análise da necessidade das pessoas, físicas e culturais, e faça do espaço um local de bem-estar e produção para o indivíduo e o coletivo. Com essa informação, percebe-se que o estudo antropológico é um importante integrante da modelação dos espaços. É necessário saber a média física dos usuários, estatura, comprimento de membros, largura, etc. Assim como também é necessário saber sobre o meio social e cultural e suas evoluções. Um exemplo de alteração cultural é inclusive citado por Ronaldo A Lidório (2009):

Se um indígena, membro de uma cultura tolerante ao infanticídio, ou mesmo fomentadora do mesmo, um dia decidir não mais participar, e até mesmo se opor a tal prática, movido por pura volição e escolha, sua história bem como de seu grupo poderá ser perpetuamente alterada desde então.

Percebe-se que na arquitetura há o estudo das cores e das formas e como elas podem interferir na mente humana, assim, determinados lugares e/ou objetos podem motivar alguma execução ou resultado por parte das pessoas. Com isso, percebe-se que ao edificar um habitat por exemplo, o arquiteto não pode somente se valer da construção em si, mas também de como o entorno, a paisagem, será capaz de trazer maior conforto aos usuários.

Um exemplo contemporâneo do uso das cores nos ambientes são os restaurantes fast-food como McDonald's que utilizam do amarelo, vermelho e laranja, espectro esse que estimula a fome e chama atenção. Além disso, também é bastante visto atualmente as cores verde e azul em ambientes de trabalho e hospitais por propiciarem calma e bem estar.

Ademais, a antropologia ao estudar as características dos objetos e produções em diferentes épocas é capaz de entender as necessidades que o homem tinha nos determinados períodos e junto com outras disciplinas como a arquitetura, determinar se esses itens poderiam vir a ser úteis se retrabalhados para a contemporaneidade como o uso de métodos de construções diferentes e até de objetos que foram esquecidos com o tempo.

Assim como acontece na moda, há na arquitetura um movimento de comportamento de grupo que segmenta as relações sociais. Segundo Silvano e Mezabarba (2019), autores de diversas disciplinas "[...] dialogam com a antropologia, perpassando problemáticas como a da construção das identidades e a da relação com o tempo." É certo então que com o tempo fica possível analisar a evolução cultural das pessoas e como esta busca usufruir do espaço e do tempo.

Os seres humanos intrinsecamente tendem a se comparar com os outros de modo que muitas vezes buscam para si os objetos ou ideais de outrem. Com isso, na arquitetura vê-se muitas casas e demais construções de um mesmo padrão de vida, seja mais rico ou mais pobre, com aparências bem próximas inclusive com imitações de detalhes. Atualmente, por exemplo, as 
fachadas das residências de condomínios fechados são basicamente um conjunto de três itens: garagem aberta, porta alta e varandão. Tal acontecimento é visível por todas cidades.

O etnólogo e antropólogo francês, Marc Augé (1992) de modo perspicaz acareou a urbanização como um confronto do homem com a cidade, trazendo assim a necessidade inevitável de evoluirmos a ideia que a antropologia e a arquitetura devem ser estudadas e executadas em similaridade. Dessa forma, torna-se o homem capaz de mudar seu entorno em prol da comunidade e vir a ser mais criativo e funcional.

Pode-se então comparar a urbanização com a metamorfose das cidades e do homem? Partindo da ideia do homem como um ensaísta modificador, sim. A cidade que herdamos sofre diversas alterações quando remodelada, as vezes de modo continuo, para atender as atuais necessidades da sociedade habitante, na tentativa de mantê-la em evolução constante em seu uso presente e futuro. "Um ensaísta é um homem simplesmente preocupado de entender o sofrimento do mundo e de transformá-lo, de remontá-lo em uma forma explicativa, implicativa e alternativa." (Didi-Huberman, 2013).

A história da civilização remete a uma estimulante evolução arquitetônica e antropológica, onde a cidade sofre uma metamorfose, partindo do pressuposto de ser algo tangível e um mero espaço construído em blocos e concreto, à uma ideia elaborada de um processo continuo entre espaço e tempo, projetado pelos indivíduos que usufruem e habitam aquele local, na esperança de tornar aquele sitio uma utopia presente e futura.

\subsection{Objetos de análise}

Existem no Brasil e no Mundo, diversos tipos de culturas e de espaços urbanos que se diferem de múltiplas maneiras desde os seus usos às suas capacidades. Cada povo tem à sua maneira de existir e coexistir.

\subsubsection{Avenida Paulista, São Paulo - SP}

A avenida é um local importante da cidade de São Paulo e é também um ponto turístico devido a diversos prédios históricos e museus como o Museu de Arte Moderna de São Paulo (MASP). Na região há diversos edifícios comerciais e nas quadras no entorno há também residenciais. É uma avenida de grande movimentação e percebe-se que os habitantes que a utilizam são apressados, estão sempre andando rápido e não é difícil encontrar pessoas correndo. Por conta disso é um grande fluxo de transeuntes seja a pé, com largos passeios disponíveis ou de veículos e até mesmo bicicletas.

Dessa forma, observa-se como a urbanização da área já foi projetada pensando em acelerar a movimentação das pessoas que já perdem muito tempo na locomoção entre casa e trabalho. Além disso, as residências e comércios são em sua maioria edifícios de múltiplos andares para usar o mínimo de área horizontal possível, visto que estas já estão escassas no local e seria inviável um aglomerado de casas na região, por exemplo. Ademais, segundo o Instituto Brasileiro de Geografia e Estatística (IBGE), o estado de São Paulo possui 10 dos 15 munícipios com maior densidade demográfica do Brasil, com uma população total de mais de 40 milhões de habitantes. Por isso é uma região que há sempre grandes fluxos de veículos e pessoas.

\subsubsection{Vitória da Conquista - BA}

É a terceira maior cidade da Bahia e teve um crescimento rápido fazendo com que o seu centro ficasse obsoleto em questões de transporte e movimentação. Os passeios são estreitos e as ruas não possuem uma configuração adequada para os dias atuais. Por conta desses problemas a cidade vem passando por diversas mudanças e até mesmo vem criando um novo Plano Diretor Urbano (PDU) para que essa urbanização seja melhor estruturada e tenha maior durabilidade.

Diferente de São Paulo, Vitória da Conquista é uma cidade de interior e não há aquela perda de tempo de horas no transporte para chegar e sair do trabalho. O tempo para atravessar toda a cidade é menor do que o de atravessar somente a 
Paulista em horário de pico, por exemplo. Percebe-se então que é uma cidade que pelo menos até então não tem o porquê de utilizar-se de avenidas com mais de três faixas ou passeios muito largos, mas que se utiliza de ciclovias por quase toda a cidade visto que esse é um meio de transporte muito comum no município.

Com essas informações fica notável como diferentes cidades devem ser pensadas de formas distintas que variam desde a cultura local ao tamanho e necessidades do espaço. Por isso os locais devem ser estudados in-loco para que sejam planejados de maneira correta atendendo a população do melhor jeito possível. Assim, consegue-se diminuir problemas de transporte evitando stress e melhorando a qualidade de vida na região.

\subsubsection{Paranapiacaba, Distrito de Santo André - SP}

É um distrito do munícipio de Santo André que faz parte da região metropolitana de São Paulo. Diferentes dos outros exemplos citados, Paranapiacaba era uma vila ferroviária e por isso possui em sua extensão diversos trilhos de trem espalhados, vários deles abandonados. Moravam na região os trabalhadores da ferrovia e também os donos de estabelecimentos.

É um ponto turístico devido à sua localidade, no alto da serra, e aos edifícios históricos, recebendo mais de 250 mil turistas anualmente. Por conta da sua altitude, por vários dias do ano, principalmente no período da tarde, a vila fica coberta por uma neblina densa. Sua formação aconteceu por conta da malha ferroviário e por isso possui uma urbanização diferenciada quando comparada aos outros estudos citados anteriormente. A cultura local é de trabalhar e morar no mesmo estabelecimento. Desta forma utiliza-se poucos veículos que inclusive têm difícil acesso para a cidade, sendo ela dividida em dois espaços que se conectam por uma ponte disponível apenas para pedestres.

Percebe-se então que como a população não utiliza muitos veículos e mantêm-se mais em sua residência/trabalho a formação da vila ocorreu pensando-se mais nos pedestres e mesmo assim por ser antiga e na serra, possui alguns lugares bastante íngremes que podem dificultar o caminhar de pessoas mais velhas e/ou com necessidades especiais. Logo, uma urbanização ao estilo da Avenida Paulista com muitas avenidas para um grande fluxo não faria sentido na região e iria contra a cultura local.

\subsection{Problemas socioculturais do meio urbano}

Com a evolução do homem a sua cidade consequentemente também passou por diversas modificações afim de atender cada vez mais as necessidades humanas individuais e coletivas, acarretando no surgimento da urbanização. Analisando o processo evolutivo das cidades, percebe-se que a grande maioria dos centros sofreram uma urbanização desordenada e acelerada, acarretando em diversos problemas sociais e culturais.

A evolução da cidade traz consigo os problemas urbanísticos, pois está ligada diretamente a industrialização. Conforme o homem evolui social e financeiramente, a sociedade passa por uma segregação, onde o indivíduo menos afortunado vê-se obrigado a emigrar para as periferias, surgindo assim um planejamento habitacional desordenado conhecido como favelização. Com isto surgem novos problemas como o déficit de transporte público, a má mobilidade urbana, a insalubridade e infraestrutura precária dessas zonas segregadas.

Estas zonas conhecidas como periferias sofrem com a falta básica de saneamento, calçamento das ruas, segurança, educação e saúde pública, etc. Devido à falta de uma política direcionada a esse déficit habitacional, a população sofre com a insalubridade, saúde precária e baixa qualificação profissional, sentindo-se lesada em meio a tantos afortunados, a conseguir atuar em um ambiente prospero para si e sua família.

Um grande passo para a resolução dos problemas sociais e culturais do Brasil seria a priorização das políticas públicas, onde estas devidamente estruturadas e focadas no bem estar da sociedade, proporcionariam uma distribuição 
igualitária de investimentos nos serviços públicos afim de sanar os déficits apresentados pela comunidade urbana. Afinal, os problemas socioculturais, ambientais e econômicos de um centro urbano não somente lesam aqueles menos afortunados, mas traz consequências para a cidade como um todo, como enchentes, inversão térmica e ilhas de calor, assim afetando todos habitantes.

A deficiência da mobilidade urbana nas cidades acarretada pela falta de estruturação do transporte público, onde este encontra-se geralmente com preços altos para a população assalariada e depredados, ocasiona o alto índice de transporte particulares nos centros urbanos, consequentemente afrontando o meio ambiente com poluição, a locomoção dos habitantes com exacerbados engarrafamentos, além de possíveis acidentes. Logo, quando se analisa a urbanização percebem-se diversas negligencias por parte dos políticos. O homem em seu egoísmo exagerado, esquece que o investimento nos âmbitos públicos gera uma melhoria para o coletivo e não somente para um. Assim, deduz-se que a urbanização das cidades deve ter como prioridade a dignidade do homem como coletivo.

\subsection{Inserção da disciplina e diferença com as já existentes}

Atualmente já existem diversas matérias ligadas à antropologia e arquitetura tal como Antropologia Urbana disponível em algumas universidades de Antropologia como a Universidade de Brasília (UnB) e a Universidade Federal do Rio de Janeiro (UFRJ). Além dela, alguns cursos de Arquitetura e Urbanismo tentam unir em uma ou algumas de suas matérias de Projeto, uma análise sociocultural do entorno em que este deve ser proposto.

Diferente da Antropologia Urbana, citada anteriormente, que possui um foco mais teórico, afastado da arquitetura e voltado aos espaços que existem ou já existiram, a proposta aqui é mais voltada para o futuro. Ou seja, além das análises urbanas atuais também deve-se entender como esses espaços funcionariam se fossem diferentes e como novos podem ser criados.

Assim, de uma forma mais ampla, a disciplina busca a melhoria dos meio urbano atual e também a melhoria dos espaços futuros, ou seja, que os consequentes projetos urbanísticos levem em conta o aprendizado para que o resultado seja um local mais útil e com mais representatividade. Então, é diferente, por exemplo, da análise sociocultural de um único entorno para um projeto como acontece em algumas faculdades. Serão feitas várias observações de diversos espaços, permitindo um maior embasamento teórico-prático das funcionalidades e a importância sociocultural dos mesmos.

\section{Conclusão}

Conclui-se que a união das disciplinas de arquitetura e antropologia permite uma melhor leitura do espaço urbano e seus elementos bem como da sociedade que ali firmará, deixando no tempo sua presença ali naquele espaço e melhorando a vivência das futuras gerações que aprenderão com os antepassados de forma cultural que o espaço é de todos. Assim, com o passar dos anos a desigualdade poderia vir a diminuir diante dessas novas leituras do urbanismo e da evolução cultural.

Além disso, percebe-se também que o ato de projetar não deve ser repetido em locais diferentes, pois, em cada lugar os indivíduos agem e usufruem do espaço de formas diferentes. Como nos estudos citados anteriormente, por exemplo, em que as pessoas em São Paulo buscam por maior facilidade de locomoção e praticidade de vida, visto que precisam aproveitar da melhor forma possível o tempo. Enquanto isso, em Paranapiacaba, os indivíduos possuem uma vida mais serena possuindo suas residências anexadas aos seus pontos de trabalho, tendo desta forma que sair menos pelas ruas.

Ademais, há lugares no mundo em que não se dá o devido valor à sociedade que ali mora, pessoas que pouco utilizam carros, são obrigadas a conviver com ruas para automóveis espalhadas pela cidade, atrapalhando o movimento de pedestres que são maioria no espaço. Logo, uma mudança no espaço urbano é necessária e para isso é preciso que haja alterações no ensino de artes e arquitetura a fim de que os futuros profissionais da área busquem sempre melhorar o espaço já existente e ao criar 
novos espaços também deixá-los o mais social possível, para ser usufruído por todos sem preconceitos e/ou separações por desigualdades sejam elas quais forem.

Portanto, é uma matéria essencial que deve ser obrigatória em todos os cursos de Arquitetura e Urbanismo, pois, é a partir dessas investigações que entendemos as pessoas, o modo de viver delas. Com isso os projetos se tornarão cada vez mais participativos diminuindo a desigualdade e o desuso dos espaços urbanos.

Uma sugestão para trabalhos futuros seria de um estudo mais prático de alguma intervenção recente e seus resultados no entorno e se foram aplicadas as pesquisas e consultas antropológicas no projeto e como isso foi ou teria sido fundamental para o espaço. Além disso, também poderia ser feita uma nova ação a algum espaço mal utilizado e fazer um artigo sobre as mudanças que esse plano teve na sociedade bem como explicar como foi a obtenção dos dados das necessidades do local.

\section{Referências} Lidório, $\quad$ R. (2009).
\%20Conceituando\%20a\%20Antropologia\%20-\%20Ronaldo\%20Lid\%F3rio.pdf.

https://revista.antropos.com.br/downloads/dez2009/Artigo\%202\%20-

Arantes, J. (2020). Desigualdade social torna o combate à COVID-19 ainda mais difícil. https://exame.com/ciencia/desigualdade-social-torna-o-combate-acovid-19-ainda-mais-dificil/.

Augé, M. (1992). Não-Lugares - introdução a uma antropologia da sobremodernidade. Editora Letra Livre.

Bermudes, B. (2016). Paranapiacaba: a descendente britânica em São Paulo. https://destinosinvisiveis.wordpress.com/2016/05/12/paranapiacaba-adescendente-britanica-em-sao-paulo/.

Biasse, A. (2018). Por uma postura antropológica de apreensão da cidade contemporânea: de uma antropologia do espaço à uma antropologia da transformação da cidade. http://www.redobra.ufba.br/wp-content/uploads/Redobra_10_23.pdf.

Chiri, R. (2014). Fotos do Museu de Arte de São Paulo - MASP. https://fotospublicas.com/o-museu-de-arte-de-sao-paulo-masp//.

Corullon, M. (2018). O que é arquitetura? https://archtrends.com/blog/o-que-e-arquitetura/?gclid=Cj0KCQjwvO2IBhCzARIsALw3ASr C4zR3cKG_fKbi0Xt8eGzNMHF4yd3p33j7V1SxOE10Ms-AYe6qd0saAtpfEALw_wcB.

Didi-huberman, G. (2013). A imagem sobrevivente. Contraponto Editora Ltda.

Eccaplan. (2016). Sustentabilidade está ligada à redução da desigualdade, defendem especialistas. https://eccaplan.com.br/blog/2016/06/24/sustentabilidadeesta-ligada-a-reducao-da-desigualdade-defendem-especialistas/.

Feldman-bianco, B. (2011). A antropologia hoje. http://dx.doi.org/10.21800/S0009-67252011000200002.

Fflhc. (2007). Antropologia. https://antropologia.fflch.usp.br/antropologia.

Francisco, W. (2018). Problemas sociais nas cidades do Brasil. https://mundoeducacao.uol.com.br/geografia/problemas-sociais-nas-cidades-brasil.htm.

Ibge. (2021). Cidades e Estados: São Paulo. https://www.ibge.gov.br/cidades-e-estados/sp/sao-paulo.html.

Kiyomura, L. (2019). União de arte e ciência é essencial para o saber, dizem pesquisadores. https://jornal.usp.br/cultura/uniao-de-arte-e-ciencia-e-essencialpara-o-saber-dizem-pesquisadores/.

Lobo, R. (2012). Linha 4 - Amarela e 5 - Lilás serão tão lotadas quanto a 3- Vermelha do Metrô, revelam estudos. https://viatrolebus.com.br/2012/08/linha4-amarela-e-5-lilas-serao-tao-lotadas-quanto-a-3-vermelha-do-metro-revelam-estudos/.

Lobo, R. (2015). Mais vias para os carros, mais trânsito. https://viatrolebus.com.br/2015/04/mais-vias-para-os-carros-mais-transito/.

Maicom. (2020). Paranapiacaba começa reabertura gradual na próxima segunda. https://abcreporter.com.br/2020/07/20/paranapiacaba-comeca-reaberturagradual-na-proxima-segunda/.

Malysse, S. (2007). Entre Arte e Antropologia: diálogos e apropriações. http://www.forumpermanente.org/painel/leituras/malysse.

Pena, R. (2020). Problemas socioambientais urbanos. https://brasilescola.uol.com.br/brasil/problemas-ambientais-sociais-decorrentes-urbanizacao.htm.

Pena, R. (2016). Problemas sociais urbanos no Brasil. https://www.preparaenem.com/geografia/problemas-sociais-urbanos-no-brasil.htm.

Pereira A. S. et al. (2018). Metodologia da pesquisa científica. Santa Maria/RS. Ed. UAB/NTE/UFSM.

Pmvc. (2013). Vitória da Conquista: uma cidade marcada pelo dinamismo econômico. https://www.pmvc.ba.gov.br/vitoria-da-conquista-uma-cidademarcada-pelo-dinamismo-economico/.

Samain, E. (2014). Antropologia, imagens e arte. Um percurso reflexivo a partir de Georges Didi-Huberman. https://journals.openedition.org/cadernosaa/391. 
Research, Society and Development, v. 10, n. 13, e386101321269, 2021

(CC BY 4.0) | ISSN 2525-3409 | DOI: http://dx.doi.org/10.33448/rsd-v10i13.21269

Sanchotene, D. (2020). Produção industrial do ES avança 5,9\% em fevereiro. https://www.agazeta.com.br/es/economia/producao-industrial-do-es-avanca-59em-fevereiro-0420.

Santo André. (2021). Vila Ferroviária de Paranapiacaba. https://www3.santoandre.sp.gov.br/turismosantoandre/vila-ferroviaria-paranapiacaba/.

Sienge Plataforma. (2021). Tudo Sobre Arquitetura. https://www.sienge.com.br/tudo-sobre-arquitetura/.

Silvano, F.; Mezabarba, R. (2019). Encontros entre Moda e Antropologia: Inícios, Debates e Perspectivas. Cadernos de Arte e Antropologia, v. 10, n. 1, p. 1527.

Stoodi. (2021). Problemas urbanos: entenda os principais problemas da urbanização. https://www.stoodi.com.br/blog/atualidades/problemas-urbanos/.

Vicente, M. (2016). Veja as cores utilizadas para aumentar as vendas em restaurantes e lanchonetes. https://www.mtall.com.br/veja-as-cores-utilizadas-paraaumentar-as-vendas-em-restaurantes-e-lanchonetes/\#: :text=Amarelo,muito\%20usadas $\% 20 \mathrm{em} \% 20 \mathrm{fast} \% 20 \mathrm{foods}$. 